\title{
On the Design of Effective E-Commerce Applications: An ISO-Based Lifecycle Model
}

\author{
Antonia Stefani ${ }^{1,2}$ \\ ${ }^{1}$ Dynamic Ambient Intelligent Sociotechnical Systems Group, Hellenic Open University, Patras, Greece \\ ${ }^{2}$ Department of Business Administration, TEI of Western Greece, Messolonghi, Greece \\ Email: stefani@eap.gr
}

How to cite this paper: Stefani, A. (2018) On the Design of Effective E-Commerce Applications: An ISO-Based Lifecycle Model. Journal of Computer and Communications, 6, 15-30.

https://doi.org/10.4236/jcc.2018.65002

Received: April 11, 2018

Accepted: May 19, 2018

Published: May 22, 2018

Copyright (c) 2018 by author and Scientific Research Publishing Inc. This work is licensed under the Creative Commons Attribution International License (CC BY 4.0).

http://creativecommons.org/licenses/by/4.0/

\begin{abstract}
The provision of services as e-commodities and the wide use of networked business models have driven buyer experience to new heights. Innovation, coupled with quality is the competitive advantage e-commerce vendors strive to achieve when designing or re-designing their software. In terms of quality, evaluation stood in the spotlight for many years. However, software analysis and design based on quality models have been used mostly for understanding, rather than improving. In this work, we present a new model for the analysis and design of e-commerce software systems mapped to the software life-cycle process. Quality control procedures are mapped to every phase, from initiation and design to delivery. Based on current ISO standards such as ISO25000 series, this work discusses technical and managerial principles that need to be applied in order to obtain quality e-commerce software.
\end{abstract}

\section{Keywords}

E-Commerce, Analysis and Design, Lifecycle, Software Quality, ISO25000

\section{Introduction}

Current buyer on-line experience is quite different from that of 10 years ago; and it continuous to change due to business and technology innovations [1]. Functionalities such as product visualization (and partial configuration), search based on customer reviews, product personalization, real-time inventory and improved post-sales support are used by the vast majority of successful e-commerce vendors. It may not be an exaggeration to state that e-commerce is being reinvented: the vision of future e-service features different navigation facets, product experience (e.g. virtual reality), social aspects, will elevate experience and sparkle greater competition [2]. 
Standardization of the procedures used for designing and developing e-commerce systems is one of the many challenges ahead. Quality standards and techniques have been successfully used for evaluation of systems and software, mainly after these systems have been delivered for use. However, research on analysis and design based on quality standards, that is, embedding quality assurance throughout the software lifecycle of e-commerce systems, is somewhat behind [3]. Since innovation along with quality of service, spearhead the effort of companies to gain a competitive advantage over their competitors, it is important to design user-intensive system with a focus on quality.

Standardization of e-commerce system design, development and management requires not only standard business processes but also a meaningful evaluation of the buying process itself. Questions on how buyers set goals and how the system functions and content is designed around those goals, how the stakeholders consume content and in which way, are some of the key research questions. Current practice relies on guidelines or the transfer of best practices [4].

In this paper, the problem of how to design effective e-commerce systems based on formal quality and assurance practices is addressed and the first steps towards formalizing such procedures through a formal standard are proposed. To this end, a top-down analysis of quality assurance needs through the definition of an e-commerce related life-cycle model is used to map processes to quality characteristics. This procedure is largely based on the significant knowledge acquired from the general use of ISO standards as evaluation guidelines for general software systems. The ultimate goal is to map needs, stakeholders and quality attributes to quality characteristics and sub-characteristics of e-commerce systems to an ISO-like standard so as to enhance analysis and design processes of such system with embedded quality assurance facets.

To this end, a new model a quality-rich life-cycle process model is presented based on ideas initially presented in [5] for other type of software systems. In this work we present a new framework for the analysis and design of e-commerce systems mapped to the software life-cycle process. Quality control procedures are mapped to every phase, from initiation and design to delivery. Based on current ISO standards such as ISO25000 series, this work discusses technical and managerial principles which need to be applied in order to obtain a complete, flexible and practical model of quality life cycle. An argument is made that business, technical and managerial principles need to be applied in order to obtain a complete, flexible and practical model of design.

The paper is organized as follows: in section 2 , the research questions are set and a brief review of the literature takes place. In section 3, the design method and lifecycle model itself is presented. Finally, section 4 presents a discussion concerning the potential use of the model.

\section{State of the Art and Research Challenges}

\subsection{General Approaches}

Quality has been long recognized as a competitive advantage in the world of 
business [6] [7]. Quality in academic terms until recent years referred mainly to usability and not so much to other system components and support services. The debate of how to implement quality assurance in e-commerce has posed many significant theoretic and practical questions concerning the links between quality and how to do business, how to manage on-line systems' quality and how much it costs [8] [9].

Traditional manufacturing as well as the services sector have employed quality management standards for many years but this does not hold so much for e-services and most particular for e-commerce. Quality Management techniques (mainly TQM-Total Quality Management) have been proposed for managing the process of e-commerce throughout its value chain but the analysis and design of the software is not tangled directly [10]. These approaches indicate the value of employing quality design in every aspect of the e-commerce system. So, although managers recognize the significance of employing quality methodologies to e-services software, most approaches are focused on processes, web design and usability [7] [11].

In this context, different perspectives of e-commerce have been researched in the past years: business, technical and user/psychological, just to mention the most important. E-commerce software "inherits" many of the properties of the above-mentioned fields, which in turn, must be engulfed deep into its analysis and design process. In the field of software design, various research efforts have been focused on web site design, user/buyer behavior and the corresponding mechanisms that enable the adaptation of content to user needs, functionality and presentation [12]. This kind of software has also been treated as a means to support the e-commerce process within an organization (managing assets from inventory control to post-sales support) [11] [13]. There are limited approaches on how to design e-commerce software using a quality approach or formal standards [14].

The present research of e-commerce software design exhibits efforts worth of merit, albeit focused on specific subsystems or functions. Table 1 presents some of the most recent research efforts in various topics, which include scientific papers with a focus on the state of the art. Design focused on website quality prevails, having to show a plethora of recent research efforts ranging from general quality management, to interface design using quality metrics and usability evaluation. Specific models and techniques (from rather older research efforts) include models such as WebQual [15], evaluation indexes relative to the goal of website functions [16] and process-based quality evaluation [17]. Modeling user behavior in order to extract design goals is a popular research subject. Numerous works research the behavior of web communities (communities of buyers) [18] [19] social aspects of e-commerce [9] [20] and user behavior [21] [22]. Analysis of big data is a recent trend fueled by the wide adoption of the software-as-a-service model and cloud computing paradigms [23]. Few of the above mentioned approaches take e-commerce software as a product or as a process 
Table 1. E-commerce specific methodologies.

\begin{tabular}{clc}
\hline Research Theme & \multicolumn{1}{c}{ References } \\
\hline \multirow{3}{*}{ Website design/Usability } & - Quality Management [17] [24] & - Quality design [15] [16] [25] [26] [27] \\
& - Quality Metrics [28] \\
& - Social and Cultural aspects [20] [29] [30] \\
& - Clickstream data/customer reviews [18] [19] [31] \\
User behavior & - Web communities [21] [22] \\
& - Big data [23] & Trust [32] \\
Security and privacy & & Privacy [33] \\
\hline
\end{tabular}

nor analyze its quality attributes in light of quality management and/or quality assessment standards.

\subsection{Process Standards}

In practice, quality management is mainly based on the application of standards such as ISO9001:2015 [34] and can be related to administrative e-business procedures. This standard defines a general quality system that can be used to support all aspects of managing a process-intensive business. This includes e-commerce by providing guidelines on how to document goals and processes, and which tangible and intangible assets are needed to operate them.

Standards that manage the lifecycle of a software development project (not e-busies specific) include IEEE1074, CMMI and ISO121207 (Table 2). These standards describe which processes are needed to develop a software system. They are mostly directed to organisations that develop the software (and not directly to those that use it-although maintenance and updates can be managed by the user-organisation). Although they do not address specific design characteristics of the software per se (but rather with the processes needed to design, develop or-in some cases-even manage it),

A general standard for managing a software development project is the Capability Maturity Model Integrated (CMMI-standardized also as an IEEE standard). As a process standard, CMMI is used for improving the development and maintenance of products and/or services [35].

IEEE1074, (IEEE Standard for Developing a Software Project Life Cycle Process) can be used as a guide (describing general indications on what to do, in which phase of the lifecycle process) but focuses more on compliance (e.g. with requirements set for the software) [36]. It is less strict than CMMI in the definition of key elements such as the organization and the number and diversity of inputs/output of processes.

ISO/IEC/IEEE12207:2017 is the newest addition to a series of process standards published from 1995 (first publication) to 2008 (previous publication). It is a common ISO and IEEE standard [37], which is rather complicated since it organizes the lifecycle of the development process to 23 processes mapped to 95 
Table 2. ISO/IEEE Process standards.

\begin{tabular}{cr}
$\begin{array}{c}\text { Standard } \\
\text { (Publication Date) }\end{array}$ & Description \\
\hline ISO9001: $2015[33]$ & $\begin{array}{r}\text { How to establish a quality system in an organization. Applies to } \\
\text { e-business, although not e-commerce specific. }\end{array}$ \\
CMMI: 2008 [34] & Processes for managing the development of software (strict). \\
IEEE1074: $2005[35]$ & Processes for managing the development of software (loose). \\
ISO/IEC/IEEE12207:2017 [36] & $\begin{array}{r}\text { Processes for managing the development of software (complete, } \\
\text { detailed, up to date). }\end{array}$
\end{tabular}

activities. It provides a common vocabulary for stakeholders engaged in various phases, a valuable contribution most standards offer. On the other hand, it has a quite large scope and its directions are general in terms of practicality: the "what to do" is described but not the "how". This is of course the case with every ISO standard that must be general enough so as to be flexible-in expense to its practicality. Since this is a new standard there is not enough evidence on its performance.

Possibly, a meaningful evaluation of the e-commerce processing itself and more precisely, of how designers set goals and how the e-commerce software is designed around those goals, is appropriate. Current practice relies on guidelines or the transfer of best practices. To the best of our knowledge, there is no e-commerce-specific or formal standard, which certifies the e-commerce process or e-commerce software.

\subsection{Evaluation Standards}

Another set of standards that may be considered more valuable to designers, are evaluation standards. These standards provide detailed insights on the specific quality attributes of a software system, thus designers can focus on what matters most as far as quality is concerned.

The notion of applying standards to user-centered design process, are based on ISO9241:2010 [38]. This standard provides requirements for designing interactive systems and provides recommendations for activities through the lifecycle of such a system. It can be applied to e-commerce software's user-interface development.

The ISO organization in a recent effort to limit the number of evaluation standards and to reduce duplication (and thus the complexity of application of standards) proceeded to issue a new series of standards over the last 5 years. The design of each model takes at least 2 years even for those who are simply updates or instructions for implementing existing ones. In the field of software design and management, ISO posted a limited number of standards until early 2013. These standards cover a wide range of prototyping processes, general guidance, data standards, specifications and software systems. A brief review of the new series of these models shows that the complexity and duplication has been reduced, but not smeared. 
With respect to software and services, important though incomplete so far, is the renewal of the ISO9126 standard through the ISO25000 series. Specific parts of the series such as ISO25010 on software and ISO25012 on data can fully replace ISO9126. Being a relatively new model (first edition March 2011), ISO25010 has not been tested extensively in the real world [39]. A more related to e-commerce, set of customer satisfaction standards, is ISO10001, ISO10002, and ISO10003 and ISO10008. They focus on the prevention and resolution of complaints, preventing customer dissatisfaction of B2C systems [40].

Table 3 presents a breakdown of ISO standards relevant/applicable to e-commerce software design.

Regarding the quality of data, particular attention is paid to the description and exchange of data between applications or systems (ISO/IEC19778-2:2008). The ISO organization has also just recently introduced the ISO27000 series standard for information security management (Table 4).

\subsection{Research Questions}

The very heart of e-commerce transactions lies in the fact that users (buyers) interact with many of the system components and respond (to buy or not to buy) offerings. The value of offerings is, in turn diverse in the sense that they may consist of intangible (services-one or more activities) or tangible (goods) assets. As in every on-line interactive software, user perception of what is usable, secure, trustworthy or easy to learn is diverse but generally, manageable in terms of adaptation (to user needs). Self-service is the key to many (or most) of the e-commerce activities such as searching for the right match and paying.

Table 3. ISO System evaluation standards.

\begin{tabular}{|c|c|}
\hline $\begin{array}{c}\text { Standard } \\
\text { (Publication Date) }\end{array}$ & Description \\
\hline ISO9126: 2008 & $\begin{array}{l}\text { Software Evaluation. Applies to all software systems. } \\
\text { Replaced by ISO } 2510 .\end{array}$ \\
\hline ISO/IEC25010:2011 & $\begin{array}{l}\text { Software Evaluation. Replaces ISO9126. Applies to all software } \\
\text { products and computer systems. Besides evaluation, it can be } \\
\text { used to control the software specification process. Many } \\
\text { features can be used to evaluate a wide range of systems and } \\
\text { services }\end{array}$ \\
\hline ISO9241:2010 & Design of interactive systems \\
\hline $\begin{array}{l}\text { ISO } 10001 \\
\text { ISO } 10002 \\
\text { ISO10004 } \\
\text { ISO10008 }\end{array}$ & $\begin{array}{l}\text { ISO10001:2007-code of conduct, } \\
\text { ISO10002:2014-complaints handling system, } \\
\text { ISO10004:2013-monitoring and } \\
\text { ISO10008-measuring customer satisfaction and provides } \\
\text { guidance for planning, designing, developing, implementing, } \\
\text { maintaining and improving an effective and efficient } \\
\text { business-to-consumer electronic commerce transaction (B2C } \\
\text { ECT) system within an organization. }\end{array}$ \\
\hline
\end{tabular}


Table 4. ISO Data and security standards.

\begin{tabular}{cc}
\hline $\begin{array}{c}\text { Standard } \\
\text { (Publication Date) }\end{array}$ & Description \\
\hline ISO/IEC19778-2:2008 & $\begin{array}{c}\text { Defines a general quality model for data kept in a } \\
\text { structured form in a computer system. It can be } \\
\text { used to define data quality requirements, quality } \\
\text { measures or for designing plans of data quality } \\
\text { assessment. }\end{array}$ \\
ISO/IEC27001:2013 & Information security management. \\
\hline ISO/IEC27000:2018 & \\
\hline
\end{tabular}

As a service, an e-commerce system can be viewed using a five facet approach: the navigation facet (where the user navigates through the functions of the software, usually a web-based component); the presentation facet where information is presented to the user by means of text, tables, images, 3-D models; the purchasing facet where the user concludes his/her transactions; the social facet where the user writes/accesses reviews, communicates with other buyers and finally the support/after sales support facet where the user is supported by the organization during and/or after a transaction. Another facet must be added (since all of above mentioned are user-specific): the interaction facet (where the software interacts with back-end applications such as inventory control, ERP, CRM or other information systems of the hosting organization). It is thus important to also take into account the "clients" within the organization that is the software and people that interact with the e-commerce system from the inside.

In traditional software development or the traditional application of quality standards, quality assessment is usually performed at the end of each phase. This means that evaluation results are available but it is rather difficult to be used for corrections since outputs are already available and changes cost. According to a basic quality assurance principle, it is best to embed quality in a process from the start than to perform quality control at the end. But how is this feasible in software engineering? Process quality standards are a first step towards this goal however they do not provide details (technical details, phase specific details) on how to achieve quality. For example, CMMI details the exact processes of the design phase but not the exact quality attributes a designer must take into account in order to design a good software. A well-designed process does not guarantee a quality outcome. There is a need to increase the practicality of the current process models and one way to achieve it is to use a combination of process and evaluation standards in an embedded form just like quality assurance proposes. Quality of the product (originating from evaluation standards) must be embedded in each process (described by the process standards). To achieve this goal, questions such as "which quality characteristics of the software are mapped (i.e. correspond strongly) with which phases of the software lifecycle process?" must be researched. For example, in the design phase of an e-commerce system, which of the quality characteristics of ISO25000 series must 
be prioritized based on the demands of the stakeholders?

Software development processes and software quality characteristics are treated independent of each other yet if they should be interconnected. According to the above-mentioned goal, there should be specifications that allow:

- compatibility of processes and quality characteristics (quality characteristics used must have meaning and significance for the stakeholders in a certain phase),

- achievement of the maximum quality by using specific quality characteristics in each phase (so only string relations should be used),

- reduction of costs (use minimum set of quality characteristics in each phase),

- reuse of quality characteristics is permitted but must be complementary.

Different types of software focus on different quality attributes. Even inside a software system, different sub-systems may be designed based on different quality goals e.g. interactivity, or security. The different facets of an e-commerce software system may also have different quality goals that must be set early on, from the design phase. It can be argued that the goal of every software system is to excel in every aspect so all quality attributes must be taken into account in every phase and in every facet. The proposed approach does not contradict this goal. However, it recognizes that in practice usually, not all aspects of a system excel in terms of quality. Especially when a system is introduced for the first time, numerous corrections are needed and this means increased costs. By focusing on what is important, qualitatively, from the beginning, costs spend for improvements may be reduced.

In order to achieve a combination of process and evaluation standards for designing and developing e-commerce software, a new life cycle model is needed. Processes of each phase need to be mapped to the important quality characteristics. This model is described in the next section.

\section{The Life-Cycle Model}

The design and development of an e-commerce software system requires both running a project (with analysis, design development and test phases) and producing a product (product view) where the product can be "continually" updated based on user reviews. Thus, the classic project lifecycle is extended to include elements of a product lifecycle and it is also refined so as to cover the specific requirements for the design and development of an e-commerce system and not those of any software system.

The design of an e-commerce software system can be regarded as a project, an approach also followed by the ISO19796/ISO25010 standards (which are however more general, covering a wide range of software applications). In the CMMI standard, a project is "the application of knowledge, tools, skills and techniques in the execution of project activities in order to meet the requirements of the stakeholders" [5]. The project phases include the Initial Phase where the objectives and the scope of the project are defined. The project is planned in detail 
using classic sub-phases such as analysis, design, development and testing. Each phase is in turn a small project with inputs/outputs, goals and results that must be validated before proceeding. This is a very general approach that although is applicable to any type of software system to be developed; it does not give the practical insights needed by designers and engineers to produce a quality outcome. The summary of the phases of the project is the project lifecycle.

Stakeholders along with several parameters that affect the outcomes are explicitly mentioned in the standard and efforts to manage them to the benefit of the project are continuous. Stakeholders are people or organizations that affect (positively or negatively) the outcome of the project. Costs, time limitations, trade-offs between quality and time/cost are also discussed and methods for overcoming quality problems and risks are taken into account.

The above analysis indicates two things: first of all, when a project for designing and developing e-commerce software is initialized, the goals (business, technical, managerial, economic) must be clear. Secondly, the process must follow the rules of project management (needs analysis, recruitment of appropriate staff, continuous evaluation of results vs. objectives etc.).

A new model is proposed that combines the product view of an e-commerce system (regarded as data, information, knowledge derived mainly from content-products or services to be sold) and the project view (where the software is analyzed designed, produced and maintained). The model thus includes additional phases that concern the analysis, design and development of information/knowledge and activities of re-use such as updates, upgrades and re-use.

A top-down procedure is used to analyze the basic phases of a software development cycle to processes that correspond to the twin view of the e-commerce system. The goal of the model is to incorporate basic parameters concerning the content of the e-commerce system and not just the services provided. This includes data idiosygracies (e.g. information about products and the services), knowledge representing the osmosis between the business/technical environment (e.g. payment processes) and the stakeholders (e.g. the business model used).The processes are then mapped to quality characteristics and sub-characteristics. This mapping is based on the quality characteristics of the ISO25000 quality standard. The goal of this mapping is to pinpoint only the strong relations between processes and quality characteristics so that designers and developers may have a practical guideline on where to focus first (or focus mainly, when resources such as time and funding are limited).

Table 5 presents the five main phases of the product lifecycle and the corresponding processes as envisaged by the proposed model. The processes includeclassic activities for producing enriched with several additional ones that refer to the content. Processes are then mapped to quality sub-characteristics derived from the ISO25000 quality standard. The sub-characteristics are organized in two categories, services (which refer to the function of the software) and content (which refer to the content used by the software). Sub-characteristics that exhibit a strong relationship with the processes and in turn, with the corresponding 
Table 5. The e-commerce life-cycle: Phases and coressponding processes mapped to Quality characteristics with a strong reltation.

\begin{tabular}{|c|c|c|}
\hline Phase & Processes & $\begin{array}{l}\text { Quality Sub-characteristics } \\
\text { (Quality Characteristics) } \\
\text { (as per ISO25000 series) }\end{array}$ \\
\hline 1) Analysis & $\begin{array}{l}\text { a) Initiation } \\
\text { b) Stakeholders definition } \\
\text { c) Define business goals } \\
\text { d) Define economic goals } \\
\text { e) Define technical requirements } \\
\text { f) Validation }\end{array}$ & $\begin{array}{l}\text { Functionality (all sub-characteristics) } \\
\text { Reliability (all sub-characteristics) } \\
\text { Usability (all sub-characteristics) } \\
\text { Efficiency (all sub-characteristics) }\end{array}$ \\
\hline 2) Design & $\begin{array}{l}\text { a) Design business model } \\
\text { b) Design content } \\
\text { c) Design services } \\
\text { d) Validation }\end{array}$ & $\begin{array}{l}\text { Content } \\
\text { - Accuracy (Functionality) } \\
\text { - Consistency (Functionality) } \\
\text { - Funtionality } \\
\text { complience (Functionality) } \\
\text { - Understandability (Usability) } \\
\text { Services } \\
\text { - Functionality } \\
\text { Completeness (Functionality) } \\
\text { - Understandability (Usability) } \\
\text { - Learnability (Usability) }\end{array}$ \\
\hline 3) Development & $\begin{array}{l}\text { a) Create services } \\
\text { b) Create content } \\
\text { c) Validation }\end{array}$ & $\begin{array}{l}\text { Content } \\
\text { - Accessibility } \\
\text { - Efficiency } \\
\text { Services } \\
\text { - User interface aesthetics (Usability) } \\
\text { - Operability (Usability) } \\
\text { - Resource Utilization(Efficiency) } \\
\text { - Time behavior (Efficiency) } \\
\text { - Fault tolerance (Reliability) }\end{array}$ \\
\hline 4) Management & $\begin{array}{l}\text { a) Use services/content } \\
\text { b) Design new services } \\
\text { c) Design new content } \\
\text { d) Validation }\end{array}$ & $\begin{array}{l}\text { Content } \\
\text { - Portability } \\
\text { Services } \\
\text { - Adaptability (Portability) }\end{array}$ \\
\hline 5) Improvement & $\begin{array}{l}\text { a) Assessment } \\
\text { b) Design Improvements } \\
\text { c) Apply Improvements } \\
\text { d) Validation }\end{array}$ & $\begin{array}{l}\text { Content } \\
\text { - Portability } \\
\text { Services } \\
\text { - Testability (Maintainability) }\end{array}$ \\
\hline
\end{tabular}

phases, are shown. The strength of the relationships is derived from the very nature of each process. For example, processes that refers to the analysis of the software exhibit strong relations with sub-characteristics that correspond to the functionality and usability of the system. This means that when a user-intensive system is designed, usually the focus is on the number of functions provided by the product and how easily the user can use them and/or learns to use them. As far as content is concerned, the design focuses on quality attributes such as accuracy (for example up to date information such as price, availability), precision (relevant and to the point information about products, rules, procedures) and consistency of information. Quality control is strengthened by introducing a va- 
lidation process at the end of each phase. Validation ensures that design guidelines implied by the quality sub-characteristics that correspond to the processes of each phase are indeed taken into account.

The life cycle includes five basic phases:

Phase 1: Requirements Analysis. This phase includes processes such as:

- Initiation: setting the initial idea and the overall objectives as well as the needs that lead to the development of business content and making initial predictions about the type of information, the budget and the delivery method.

- Stakeholders definition: who (people, systems will be involved) and how (directly, indirectly, in which phase and process and what is their impact)?

- Define business goals: setting out the business goals for the e-commerce system is very important for the final configuration of the software. Business goals are linked to the specific target groups, which in turn are linked to specific content and e-services, provided by the system.

- Economic goals definition is often considered a sub-set of business goals. However, they include costs (direct or indirect) that must be taken into account when considering both the business and technical requirements. For example, the use of expensive third party services for searching functions or after sales support may increase the total expenses of running the software and post barriers on running other processes such as updates/upgrades or extensions.

- Technical requirements are defined after business and economic goals are set. This helps the more pragmatic definition of technical specifications for both services and content.

Phase 2: In the design phase, the business goals are transformed into the business model that the software will support. This is actually an alignment of the conditions that dictate when added business value is generated and how the software meets these conditions. Since market conditions may change, the design should support solutions to new business problems that may require process or organizational changes. Technical requirements are detailed to software specifications for both services (functionality) and content (information). Content quality is strongly linked to requirements such as precision, currency consistency and understandability:

- Accuracy refers to the correctness of information in a specific context of use.

- Consistency refers to contradiction-free and coherent data.

- Understandability refers to the degree to which data has attributes that enable it to be read and interpreted by users of a specific context.

- Compliance refers to the ability of information to adhere to standards, conventions or regulations in the specific context of use.

Service quality is closely linked to the following quality attributes (besides understandability which also refers to data as well as to services):

- Functional completeness: ideally, the design should include functions that cover all the specified tasks and user objectives. 
- Learnability: the ability of services to be learned in an as short period of time as possible so as to be used with effectiveness, efficiency, freedom from risk and satisfaction in a specified context of use.

Phase 3: In the development phase, the services and the content are developed according to the specifications derived from the previous phase. An optional process where content and services are assessed may take place before the end of the phase to study the satisfaction of user expectations (business objectives, functions, technical environment) at an early stage (before the product reaches the customer).

Content quality:

- Accessibility refers to the ability of information to be accessed as intended in a specific context of use.

- Efficiency refers to ability of information to be processed and provide the expected levels of performance by using the defined amounts and types of resources provided by the system.

Service quality is strongly linked to:

- User interface aesthetics refers to the interaction between the user and the system.

- Operability refers to the easiness with which the system is operated and controlled.

- Time behavior refers to response and processing times of the software.

- Resource utilization refers to the amount of resources used by the software during its operation and whether this amount is within defined limits.

- Fault tolerance refers to the ability if the software to operate despite the presence of faults.

Phase 4: the Management phase includes the use of services and content, which sometimes involves considerable indirect costs (e.g. from updating the product database, updating product characteristics). Services can also be upgraded or maintained depending on user expectations or market changes.

Content quality is loosely linked to the same characteristics as in the previous phase. In the case of content update and is additionally linked to:

- Portability refers to the ability of data to be re-used by other services or systems.

Service quality refers mainly to internal software quality:

- Adaptability refers to ability of the software to be adapted.

Phase 5: Assessment/Improvement. This last phase includes processes involving the design and development of improvements that have become necessary after its use. These changes may be traced and documented after the assessment of the software by the stakeholders. Design modifications involve repetition (of all or of some) of the processes of Phase 2.

\section{Discussion and Conclusions}

The model is based on the mapping of phases and processes of the model to 
quality characteristics and sub-characteristics of a hierarchical standard structure (as the one used by ISO standards). The approach presented relies on the quality standards of the ISO/IEC25000 series and especially on ISO/IEC25010 (Software engineering-Software product Quality Requirements and Evaluation (SQuaRE) Quality model), the ISO/IEC25012 (SQuaRE quality model-Data quality model) and ISO25020 (measurement method).

The philosophy of this approach is to use the same model, but different evaluation approaches depending on the stage of the life cycle and the facet of the content that is being evaluated.

As in other ISO standards, content evaluation, from the developer's side of view, is mapped to internal quality characteristics. External quality is used for content assessment when the later is in use by real users or evaluators. Quality in use refers to the level of satisfaction of the buyers while using the content and emphasizes on their behavior during use rather than the characteristics of the content per se.

According to ISO25010, quality evaluation happens in three main phases of a product life cycle: when the product is under construction, when the product is being evaluated and when phase the product is in use. Following the methodology of the series 25000 standards, internal, external quality and quality in use are associated with the phases of the content lifecycle. In this context, quality (and hence is characteristics) are connected to the content life cycle.

The requirements for quality in use determine the required level of quality from the users' perspective (buyers' internal users). These requirements are used to validate the product by users. They can be determined by specific quality in use metrics.

In turn, these requirements contribute to the definition of requirements for external quality. The latter are used for validation (validation \& verification) of the content. These requirements can be further expressed quantitatively through external quality measures and used as criteria for evaluation.

The quality model can be applied as a guide for the design, creation and evaluation of e-commerce software and its corresponding content. External requirements contribute to the specification of internal quality requirements and which are, in turn, used to predict the requirements of quality in use. This creates a cycle, where the requirements of one category contribute to the specification of the requirements of next one; requirements are specified in the form of quantitative metrics measures.

\section{References}

[1] Qin, Z., Chang, Y., Li, S. and Li, F. (2014) Technical E-Commerce Strategy. In: Zheng, Q., Ed., E-Commerce Strategy, Springer, Berlin, Heidelberg, 313-348. https://doi.org/10.1007/978-3-642-39414-0_6

[2] Chen, L. and Holsapple, C.W. (2013) E-Business Adoption Research: State of the Art. Journal of Electronic Commerce Research, 14, 261-286.

[3] Zheng, Q., Han, Y., Li, S., Dong, J., Yan, L. and Qin, J. (2009) E-Commerce Archi- 
tecture and System Design. In: Zheng, Q., Ed., Introduction to E-Commerce, Springer, Berlin, Heidelberg, 271-303. https://doi.org/10.1007/978-3-540-49645-8_8

[4] Yang, Z., Shi, Y. and Yan, H. (2016) Scale, Congestion, Efficiency and Effectiveness in E-Commerce Firms. Electronic Commerce Research and Applications, 20, 171-182. https://doi.org/10.1016/j.elerap.2016.07.003

[5] Stefani, A. and Kameas, A. (2013) Educational Content in Open and Distance Learning Environments: An Insight into the Use of Standards and Guidelines for Evaluation. Proceedings of the 17 th Panhellenic Conference on Informatics, Thessaloniki, September 19-21 2013, 227-234. https://doi.org/10.1145/2491845.2491879

[6] Xu, H. and Koronios, A. (2016) Understanding Information Quality in E-Business. Journal of Computer Information Systems, 45, 73-82.

[7] Adolphs, C. and Winkelmann, A. (2010) Personalization Research in E-Commerce-A State of the Art Review (2000-2008). Journal of Electronic Commerce Research, 11, 326-341.

[8] Mohanty, R.P., Seth, D. and Mukadam, S. (2010) Quality Dimensions of E-Commerce and Their Implications. Total Quality Management \& Business Excellence, 18, 219-247. https://doi.org/10.1080/14783360601149992

[9] Corbae, G., Jensen, J.B. and Schneider, D. (2003) Marketing 2.0: Strategies for Closer Customer Relationships. Springer, Berlin. https://doi.org/10.1007/978-3-540-24783-8

[10] Kotian, H. and Meshram, B.B. (2017) A Framework for Quality Management of E-Commerce Websites. 2017 International Conference on Nascent Technologies in Engineering, Navi Mumbai, 27-28 January 2017, 1-6. https://doi.org/10.1109/ICNTE.2017.7947975

[11] Cudjoe, D. (2014) Electronic Commerce: State-of-the-Art. American Journal of Intelligent Systems, 4, 135-141.

[12] Billewar, S.R. and Babu, D.H. (2012) Approach to Improve Quality of E-Commerce. International Journal of Recent Technology and Engineering, 31, 36-39.

[13] Kong, Z. and Li, M. (2015) Research on Elements and Method of Evaluating B2C E-Commerce Service Quality Based on QFD. In: Qi, E., Su, Q., Shen, J., Wu, F. and Dou, R., Eds., Proceedings of the 5 th International Asia Conference on Industrial Engineering and Management Innovation, Atlantis Press, Paris, 17-25. https://doi.org/10.2991/978-94-6239-100-0_4

[14] Adikara, F., Sandfreni, Anggarani, A. and Ernawati (2018) Qualitative Requirements Analysis Process in Organization Goal-Oriented Requirements Engineering (OGORE) for E-Commerce Development. In: Kim, K., Kim, H. and Baek, N., Eds., IT Convergence and Security 2017, Lecture Notes in Electrical Engineering, Springer, Singapore, 318-324.

[15] Loiacono, E.T. (2000) WebQual ${ }^{\mathrm{TM}}$ : A Web Site Quality Instrument. Ph.D. Thesis, University of Georgia, Athens, GA.

[16] Zhu, X.N. and Wu, F.P. (2013) Research on a Comprehensive Evaluating Model of E-Commerce Website Design Based on AHP. Advanced Materials Research, 756-759, 810-813. https://doi.org/10.4028/www.scientific.net/AMR.756-759.810

[17] Dragulanescu, N.G. (2013) Website Quality Evaluations: Criteria and Tools. International Information \& Library Review, 34, 247-254. https://doi.org/10.1080/10572317.2002.10762580

[18] Chiu, C.-M., Wang, E.T.G., Fang, Y.-H. and Huang, H.-Y. (2014) Understanding Customers' Repeat Purchase Intentions in B2C E-Commerce: The Roles of Utilitarian Value, Hedonic Value and Perceived Risk. Information Systems Journal, 24, 
85-114. https://doi.org/10.1111/j.1365-2575.2012.00407.x

[19] Olbrich, R. and Holsing, C. (2011) Modeling Consumer Purchasing Behavior in Social Shopping Communities with Clickstream Data. International Journal of Electronic Commerce, 16, 15-40. https://doi.org/10.2753/JEC1086-4415160202

[20] Busalim, A.H. and Hussin, A.R.C. (2016) Understanding Social Commerce: A Systematic Literature Review and Directions for Further Research. International Journal of Information Management, 36, 1075-1088. https://doi.org/10.1016/j.ijinfomgt.2016.06.005

[21] Brengman, M. and Karimov, F.P. (2012) The Effect of Web Communities on Consumers' Initial Trust in B2C E-Commerce Websites. Management Research Review, 35, 791-817. https://doi.org/10.1108/01409171211256569

[22] Huseynov, F. and Yıldırım, S.O. (2015) Behavioral Issues in B2C E-Commerce: The-State-of-the-Art. Information Development, 32, 1343-1358. https://doi.org/10.1177/0266666915599586

[23] Jackson, L. (2016) E-Commerce. Big Data, Big Security and the Value for Customers and Companies. GRIN Verlag, USA.

[24] Leite, P., Gonçalves, J., Teixeira, P. and Rocha, A. (2014) Towards a Model for the Measurement of Data Quality in Websites. New Review of Hypermedia and Multimedia, 20, 301-316. https://doi.org/10.1080/13614568.2014.968638

[25] Rekik, R., Kallel, I., Casillas, J. and Alimi, A.M. (2018) Assessing Web Sites Quality: A Systematic Literature Review by Text and Association Rules Mining. International Journal of Information Management, 38, 201-216. https://doi.org/10.1016/j.ijinfomgt.2017.06.007

[26] Selcuk, C. (2013) A Quality Evaluation Model for the Design Quality of Online Shopping Websites. Electronic Commerce Research and Applications, 12, 124-135. https://doi.org/10.1016/j.elerap.2012.12.001

[27] Jinling, C., Tong, S., Chuncan, L. and Tao, S. (2009) Modeling E-Commerce Website Quality with Quality Function Deployment. 2009 IEEE International Conference on E-Business Engineering, Macau, 21-23 October 2009, 417-422. https://doi.org/10.1109/ICEBE.2009.65

[28] Stefani, A. and Xenos, M. (2009) Meta-Metric Evaluation of E-Commerce-Related Metrics. Electronic Notes in Theoretical Computer Science, 233, 59-72. https://doi.org/10.1016/j.entcs.2009.02.061

[29] Huang, Z. and Benyoucef, M. (2017) The Effects of Social Commerce Design on Consumer Purchase Decision-Making: An Empirical Study. Electronic Commerce Research and Applications, 25, 40-58. https://doi.org/10.1016/j.elerap.2017.08.003

[30] Díaz, J., Rusu, C. and Collazos, A. (2017) Experimental Validation of a Set of Cultural-Oriented Usability Heuristics: E-Commerce Websites Evaluation. Computer Standards \& Interfaces, 50, 160-178. https://doi.org/10.1016/j.csi.2016.09.013

[31] Trenz, M. and Berger, B. (2013) Analyzing Online Customer Reviews-An Interdisciplinary Literature Review and Research Agenda. Proceedings of the 21 th European Conference on Information Systems, Utrecht, 6-8 June 2013, 1-12.

[32] Greiner, M.E. and Wang, H. (2010) Building Consumer-to-Consumer Trust in E-Finance Marketplaces: An Empirical Analysis. International Journal of Electronic Commerce, 15, 105-136. https://doi.org/10.2753/JEC1086-4415150204

[33] Xu, H., Liu, D., Wang, H. and Stavrou, A. (2017) An Empirical Investigation of Ecommerce-Reputation-Escalation-as-a-Service. ACM Transactions on the Web, 11, Article No. 13. https://doi.org/10.1145/2983646

[34] ISO Organisation (2015) ISO9001:2015. Quality Management Systems. Geneva. 
[35] Chrissis, M.B., et al. (2007) Guidelines for Process Integration and Product Development. CMMI Second Edition, Addison-Wesley, Boston.

[36] IEEE (1992) 1074-1991-IEEE Standard for Developing a Software Project Life Cycle Process. Piscataway Township. https://doi.org/10.1109/IEEESTD.1992.101080

[37] IEEE (2017) 12207-2017-ISO/IEC/IEEE International Standard-Systems and Software Engineering-Software Life Cycle Processes. 1st Edition, Piscataway Township. https://doi.org/10.1109/IEEESTD.2017.8100771

[38] International Organization for Standardization (2010) Ergonomics of Human-System Interaction-Part 210: Human-Centred Design for Interactive Systems. ISO9241-210:2010.

[39] International Organization for Standardization (2011) Systems and Software Engineering-Systems and Software Quality Requirements and Evaluation (SQuaRE)—System and Software Quality Models. ISO/IEC25010:2011

[40] International Organization for Standardization (2007) Quality Management-Customer Satisfaction-Guidelines for Codes of Conduct for Organizations. ISO10001:2007 